\title{
Utility of preoperative in vitro platelet function tests for predicting bleeding risk in patients undergoing functional endoscopic sinus surgery
}

This article was published in the following Dove Press journal:

Journal of Blood Medicine

21 October 2016

Number of times this article has been viewed

\section{A-Jin Lee \\ Sang-Gyung Kim}

Department of Laboratory Medicine, Catholic University of Daegu School of Medicine, Daegu, Republic of Korea
Correspondence: A-Jin Lee Department of Laboratory Medicine, Catholic University of Daegu School of Medicine, 33, Duryugongwon-ro 17-gil, Nam-gu, Daegu 42472, Republic of Korea $\mathrm{Tel}+82536504102$

Fax +82536538672 Email ajlee388@gmail.com.
Background: It is necessary to predict the bleeding risk in patients undergoing functional endoscopic sinus surgery (FESS). To evaluate the adequacy of primary hemostasis, preoperative hemostatic screening tests are used. In the present study, we determined whether there is a positive correlation between prolonged closure time (CT) with collagen/epinephrine (CT-epi), prothrombin time (PT), international normalized ratio (INR), activated partial thromboplastin time (aPTT) and bleeding during FESS.

Patients and methods: We reviewed the medical records of 90 patients without bleeding histories who had undergone FESS from March 2013 to June 2014. More than $200 \mathrm{~mL}$ of blood loss was defined as moderate bleeding during surgery. With respect to bleeding during surgery, we determined the sensitivity, specificity, negative predictive value (NPV) and positive predictive value (PPV) of CT-epi, PT, INR and aPTT.

Results: Of the 90 patients, 17 (18.9\%) patients had preoperative prolonged CT values and three (17.6\%) patients had bleeding. In comparison, five $(6.8 \%)$ of the $73(81.1 \%)$ patients who had undergone FESS with preoperative normal PFA values experienced bleeding $(P=0.171)$. On the other hand, patients with prolonged PT values $(2,2.2 \%)$, prolonged INR values $(3,3.3 \%)$ or prolonged PTT values $(1,1.1 \%)$ had no bleeding episode. Preoperative CT had low sensitivity (44.4\%) and PPV (23.5\%).

Conclusion: During preoperative period, the hemostatic screening may not be helpful to detect the bleeding tendency in adult patients undergoing FESS. Routine measurement of CT-epi, PT, INR and aPTT for preoperative screening may not be recommended for FESS patients.

Keywords: bleeding time, platelet function tests, blood coagulation tests, surgery, screening

\section{Background}

It has been demonstrated that $-3-5 \%$ of patients undergoing surgery have an acquired platelet defect, a congenital platelet defect or von Willebrand disease. ${ }^{1}$ Ongoing and postoperative bleeding are the most frequent complications in patients undergoing functional endoscopic sinus surgery (FESS) or septoplasty. ${ }^{2}$ Intraoperative bleeding narrows surgical field and hinders the recognition of anatomical references and the drainage routes of the paranasal sinuses. ${ }^{3}$

Operation without any hemostatic screening test results may lead to increased morbidity and mortality. In addition, perioperative hemorrhage may require the administration of blood products to correct a deficit of red blood cells or underlying or resulting coagulopathy. The risks of blood transfusion also cause increased morbidity and mortality. Therefore, it is critical to predict the risk of perioperative or postoperative bleeding in patients undergoing surgery. 
Coagulation screening tests such as prothrombin time (PT), international normalized ratio (INR) and activated partial thromboplastin time (aPTT) are routinely used to screen for defects of the coagulation pathway. Several studies have been carried out to measure the utility of preoperative hemostatic screening in different surgical populations. ${ }^{4-6} \mathrm{To}$ evaluate the adequacy of primary hemostasis, the bleeding time test has been used for many years. However, this test has low sensitivity and is an invasive procedure; therefore, its use has declined. In vitro platelet function tests, using a platelet function analyzer (PFA) such as PFA-100 (DadeBehring, Dudingen, Switzerland), which was introduced to detect impaired hemostasis in the mid-1990s, have gained popularity. Closure time (CT) in the membranes coated with collagen/epinephrine or collagen/ADP can be determined using a PFA. ${ }^{7}$ The abnormal CT values were detected in $100 \%$ of von Willebrand's disease patients. In contrast, the bleeding time (BT) was normal in about one-third of patients with von Willebrand disease. ${ }^{8}$ However, PFA also has disadvantages. The CT value is affected by von Willebrand factor level, blood type or antiplatelet agents. ${ }^{9-11}$ Although CT values are commonly measured for preoperative hemostatic screening, the utility of CT values is controversial, and studies of predicting the bleeding risk in CT are rare especially in FESS.

In this study, we determined whether there is a positive correlation between prolonged $\mathrm{CT}$ with collagen/epinephrine (CT-epi), PT, INR, aPTT and bleeding during FESS. We determined the sensitivity, specificity, negative predictive value (NPV) and positive predictive value (PPV) of CT-epi, PT, INR and aPTT.

\section{Patients and methods}

\section{Patients}

We retrospectively reviewed the medical records of 90 patients who had undergone FESS from March 2013 to June 2014 in one hospital. The study did not include any patients with known hemostatic disorders or patients taking medicine of anticoagulation. All information was obtained from the hospital's electronic medical records. Ethical approval and patient consent was deemed not necessary by the Institutional Review Board at Daegu Catholic University Medical Center due to the retrospective nature of this study.

\section{Laboratory analysis}

The patient population was classified into prolonged and normal groups according to the laboratory results of CT-epi (PFA-100), PT, INR and aPTT (STA-R analyzer; Diagnostica Stago, Asnières Sur Seine, France). All CT-epi values $>192$ s,
PT value $>15.0$ s, INR values $>1.2$ and aPTT values $>45.0 \mathrm{~s}$ were defined as prolonged, and all results below these values were defined as normal. The cut-off values were determined by reference ranges in our laboratory. Bleeding during surgery was determined according to the medical records by the operating physician and/or anesthesiologist. More than $200 \mathrm{~mL}$ of blood loss was defined as moderate bleeding during surgery.

\section{Statistical analysis}

Statistical analysis was performed using the SPSS software, version 19.0 (SPSS, Chicago IL, USA). Categorical data were compared using the Fisher's exact test. We determined the sensitivity, specificity, NPV and PPV using 2'2 correlation tables by the preoperative CT-epi/PT/INR/aPTT values versus bleeding outcome. $P<0.05$ was considered statistically significant.

\section{Results}

\section{Patient characteristics}

We reviewed the electronic medical records of 90 patients with an age range of $20-82$ years ( $51.5 \pm 14.1$ years). Of them, $34(37.8 \%)$ were females and $56(62.2 \%)$ were males. These patients underwent FESS. The surgery was performed by the same surgeon in all patients.

\section{CT-collagen/epinephrine test results}

A total of 17 (18.9\%) patients had prolonged CT-epi values and $73(81.1 \%)$ had normal CT-epi values in their preoperative tests (Table 1). Three (17.6\%) of the 17 (18.9\%) patients who underwent surgery with preoperative prolonged CT-epi values at first testing experienced bleeding episodes during surgery, but five $(6.8 \%)$ of the $73(81.1 \%)$ patients who underwent surgery with preoperative normal CT-epi values experienced bleeding episodes during surgery $(P=0.171)$.

Table I Summary of research data for preoperative CT-epi, PT, INR and aPTT

\begin{tabular}{llll}
\hline Group & $\begin{array}{l}\text { Group } \\
\text { size (\%) }\end{array}$ & $\begin{array}{l}\text { Moderate bleeding } \\
\text { during surgery (\%) }\end{array}$ & P-value \\
\hline Prolonged CT-epi $(\geq 192 \mathrm{~s})$ & $17(18.9)$ & $3(17.6)$ & $0.17 \mid$ \\
Normal CT-epi $(<192 \mathrm{~s})$ & $73(81.1)$ & $5(6.8)$ & \\
Prolonged PT $(\geq \mid 5 s)$ & $2(2.2)$ & $0(0.0)$ & 1.000 \\
Normal PT $(<\mid 5 s)$ & $88(97.8)$ & $8(9.1)$ & \\
Prolonged INR $(\geq 1.2)$ & $3(3.3)$ & $0(0.0)$ & 1.000 \\
Normal INR $(<1.2)$ & $87(96.7)$ & $8(9.2)$ & \\
Prolonged aPTT $(\geq 45 s)$ & $I(1.1)$ & $0(0.0)$ & 1.000 \\
Normal aPTT $(<45 s)$ & $89(98.9)$ & $8(9.0)$ & \\
\hline
\end{tabular}

Abbreviations: CT-epi, closure time with collagen/epinephrine; PT, prothrombin time; INR, international normalized ratio; aPTT, activated partial thromboplastin time. 


\section{PT test results}

A total of 88 (97.8\%) patients had normal PT values and two $(2.2 \%)$ patients had prolonged PT test results in their preoperative tests (Table 1). Neither ( $0.0 \%)$ of the two $(2.2 \%)$ patients who underwent surgery with preoperative prolonged PT results at first testing experienced bleeding episodes during surgery, but eight $(9.1 \%)$ of the $88(97.8 \%)$ patients who had undergone surgery with preoperative normal PT values experienced bleeding during surgery.

\section{INR test results}

A total of 87 (96.7\%) patients had normal INR values and three (3.3\%) patients had prolonged INR test results in their preoperative tests (Table 1). Eight (9.2\%) of the 87 (96.7\%) patients who underwent surgery with preoperative normal INR values experienced bleeding episodes during surgery, but none $(0.0 \%)$ of the three $(3.3 \%)$ patients who had undergone surgery with preoperative prolonged INR values experienced bleeding during surgery.

\section{aPTT test results}

A total of $89(98.9 \%)$ patients had normal aPTT values and only one (1.1\%) patient had prolonged aPTT test result in their preoperative tests (Table 1). Eight (9.0\%) of the 89 $(98.9 \%)$ patients who underwent surgery with preoperative normal aPTT values experienced bleeding episodes during surgery, but one $(1.1 \%)$ patient who had undergone surgery with preoperative prolonged aPTT value does not experience bleeding during surgery.

\section{Diagnostic utility}

Preoperative CT-epi had $44.4 \%$ of sensitivity and $23.5 \%$ of PPV. The other results of sensitivity, specificity, NPV and PPV are shown in Table 2.

\section{Discussion}

Coagulation screening tests have been widely used in preoperative setting. The aim of this study was to analyze the

Table 2 Validity values for preoperative CT-epi, PT, INR and aPTT

\begin{tabular}{lllll}
\hline $\begin{array}{l}\text { Laboratory } \\
\text { test item }\end{array}$ & $\begin{array}{l}\text { Sensitivity } \\
\text { (\%) }\end{array}$ & $\begin{array}{l}\text { Specificity } \\
(\%)\end{array}$ & $\begin{array}{l}\text { Positive } \\
\text { predictive } \\
\text { value (\%) }\end{array}$ & $\begin{array}{l}\text { Negative } \\
\text { predictive } \\
\text { value (\%) }\end{array}$ \\
\hline CT-epi & 44.4 & 84.0 & 23.5 & 93.2 \\
PT & 0.0 & 97.5 & 0.0 & 89.8 \\
INR & 0.0 & 96.3 & 0.0 & 89.7 \\
aPTT & 0.0 & 98.8 & 0.0 & 89.9 \\
\hline
\end{tabular}

Abbreviations: CT-epi, closure time with collagen/epinephrine; PT, prothrombin time; INR, international normalized ratio; aPTT, activated partial thromboplastin time. diagnostic utility of the CT-epi values and other coagulation screening tests for the bleeding tendency in defined subgroup of patients undergoing FESS. FESS is a surgical procedure using a fiber optic camera. During this surgery, bleeding may impair the surgical field. ${ }^{12}$ Intraoperative bleeding can increase the operation risk and time. Postoperative bleeding may complicate the recovery of ventilation and drainage. ${ }^{13}$ Therefore, it is necessary to predict bleeding risk before surgery. However, the preoperative screening of platelet function before FESS has been rarely investigated.

In the present study, the routine coagulation screening tests including PT, INR and aPTT infrequently detected the bleeding tendency. Previous studies have also reported that preoperative PT/PTT in patients with negative bleeding histories is the poor predictor of bleeding showing the low PPV (0.03-0.22) and likelihood ratio (0.94-5.1). ${ }^{14-16}$

Although it has been demonstrated that the $\mathrm{CT}$ value is more sensitive than $\mathrm{BT}$ in the assessment of von Willebrand disease, ${ }^{1}$ the benefit of CT value is controversial in preoperative screening. Although the frequency of bleeding episodes was higher $(17.6 \%)$ in patients with prolonged CT-epi values than in patients with prolonged PT, INR or aPTT in the present study, there was no statistical difference between patients with prolonged CT-epi values and patients with normal CT-epi values $(P=0.171)$. Results of the present study are similar to those of the earlier study, which reported that $\mathrm{CT}$ values are not necessary in general unselective screening. ${ }^{17}$ It has been reported that the PFA100 result during the perioperative period cannot predict the intensity of perioperative bleeding in patients undergoing neurosurgery, heart surgery or hemiarthroplasty. ${ }^{18-20}$ It has been demonstrated that the preoperative PFA-100 analysis can be a helpful predictor of perioperative hemorrhage only in patients with positive bleeding histories. ${ }^{21}$ However, Koscielny ${ }^{22}$ reported that PFA-100 analysis as a screening test could detect impaired hemostasis in 5,649 unselected adult patients. It has been reported that the PFA-100 could detect bleeding disorder well in children. ${ }^{23}$ In the present study, however, the patients included were all adults without bleeding disorders.

We have validated the value of predicting the bleeding risk during FESS in patients without bleeding disorders. The sensitivity and the PPV of prolonged CT-epi values were higher (44.4 and $23.5 \%$, respectively) compared with that of other screening tests. The specificity and the NPV of prolonged CT-epi values were 84.0 and $93.2 \%$, respectively. The CT values obtained from PFA are characterized by a high NPV. ${ }^{24}$ 
This study has a limitation stemming from its small sample size. This is a retrospective study; therefore, it is susceptible to bias in the assessment of bleeding. It would be helpful to assess the bleeding history using standardized questionnaire to avoid bias. These coagulation laboratory assays in the present study are in vitro assays, and they do not accurately reflect the in vivo hemostatic response.

\section{Conclusion}

During preoperative period, the hemostatic screening may not be helpful to detect the bleeding tendency in adult patients undergoing FESS without bleeding histories. Routine measurement of CT-epi values for preoperative screening may not be recommended in the absence of bleeding histories.

\section{Acknowledgment}

This work was supported by research grants from the Catholic University of Daegu in 2014.

\section{Disclosure}

The authors report no conflicts of interest in this work.

\section{References}

1. Harrison P. The role of PFA-100R testing in the investigation and management of haemostatic defects in children and adults. Br J Haematol. 2005;130(1):3-10.

2. Gross RD, Sheridan MF, Burgess LP. Endoscopic sinus surgery complications in residency. Laryngoscope. 1997;107(8):1080-1085.

3. Stankiewicz JA. Complications in endoscopic intranasal ethmoidectomy: an update. Laryngoscope. 1989;99(7 Pt 1):686-690.

4. AsafT, Reuveni H, Yermiahu T, et al. The need for routine pre-operative coagulation screening tests (prothrombin time PT/partial thromboplastin time PTT) for healthy children undergoing elective tonsillectomy and/or adenoidectomy. Int J Pediatr Otorhinolaryngol. 2001;61(3):217-222.

5. Martin JH, Rosser CJ, Linebach RF, McCullough DL, Assimos DG. Are coagulation studies necessary before percutaneous nephrostomy? Tech Urol. 2000;6(3):205-207.

6. Ng KFJ, Lai KW, Tsang SF. Value of preoperative coagulation tests: reappraisal of major noncardiac surgery. World J Surg. 2002;26(5):515-520.

7. Francis J, Francis D, Larson L, et al. Can the platelet function analyzer (PFA®)-100 test substitute for the template bleeding time in routine clinical practice? Platelets. 1999;10(2-3):132-136.
8. Fressinaud E, Veyradier A, Truchaud F, et al. Screening for von Willebrand disease with a new analyzer using high shear stress: a study of 60 cases. Blood. 1998;91(4):1325-1331.

9. Böck M, Haan D, Beck KH, et al. Standardization of the PFA-100® platelet function test in $105 \mathrm{mmol} / \mathrm{l}$ buffered citrate: effect of gender, smoking, and oral contraceptives. Br J Haematol. 1999;106(4):898-904.

10. Haubelt H, Anders C, Vogt A, Hoerdt P, Seyfert UT, Hellstern P. Variables influencing platelet function analyzer-100TM closure times in healthy individuals. Br J Haematol. 2005;130(5):759-767.

11. Favaloro EJ. Clinical application of the PFA-100®. Curr Opin Hematol. 2002;9(5):407-415.

12. Drozdowski A, Sieśkiewicz A, Siemiatkowski A. Reduction of intraoperative bleeding during functional endoscopic sinus surgery. Anestezjol Intensywna Ter. 2011;43(1):45-50.

13. Baumann A, Caversaccio M. Hemostasis in endoscopic sinus surgery using a specific gelatin-thrombin based agent (FloSeal). Rhinology. 2003;41(4):244-249.

14. Gabriel P, Mazoit X, Ecoffey C. Relationship between clinical history, coagulation tests, and perioperative bleeding during tonsillectomies in pediatrics. J Clin Anesth. 2000;12(4):288-291.

15. Chee YL, Crawford JC, Watson HG, Greaves M. Guidelines on the assessment of bleeding risk prior to surgery or invasive procedures: British Committee for Standards in haematology. $\mathrm{Br} J$ Haematol. 2008;140(5):496-504.

16. Seicean A, Schiltz NK, Seicean S, et al. Use and utility of preoperative hemostatic screening and patient history in adult neurosurgical patients: clinical article. J Neurosurg. 2012;116(5):1097-1105.

17. Roschitz B, Thaller S, Koestenberger M, et al. PFA-100 closure times in preoperative screening in 500 pediatric patients. Thromb Haemost. 2007;98(1):243-247.

18. Karger R, Reuter K, Rohlfs J, Nimsky C, Sure U, Kretschmer V. The platelet function analyzer (PFA-100) as a screening tool in neurosurgery. ISRN Hematol. 2012;2012:1-7.

19. Fattorutto M. Does the platelet function analyser (PFA-100(R)) predict blood loss after cardiopulmonary bypass? Br J Anaesth. 2003;90:692-693.

20. Thaler HW, Frisee F, Korninger C. Platelet aggregation inhibitors, platelet function testing, and blood loss in hip fracture surgery. JTrauma Inj Infect Crit Care. 2010;69(5):1217-1221.

21. Görlinger K, Jambor C, Hanke AA, et al. Perioperative coagulation management and control of platelet transfusion by point-of-care platelet function analysis. Transfus Med Hemother. 2007;34(6):396-411.

22. Koscielny J. A practical concept for preoperative identification of patients with impaired primary hemostasis. Clin Appl Thromb Hemost. 2004;10(3):195-204.

23. Guay J, Faraoni D, Bonhomme F, Borel Derlon A, Lasne D. Ability of hemostatic assessment to detect bleeding disorders and to predict abnormal surgical blood loss in children: a systematic review and metaanalysis. Pediatr Anesth. 2015;25(12):1216-1226.

24. Paniccia R, Priora R, Liotta AA, Abbate R. Platelet function tests: a comparative review. Vasc Health Risk Manag. 2015;11:133-148.
Journal of Blood Medicine

\section{Publish your work in this journal}

The Journal of Blood Medicine is an international, peer-reviewed, open access, online journal publishing laboratory, experimental and clinical aspects of all aspect pertaining to blood based medicine including but not limited to: Transfusion Medicine; Blood collection, Donor issues, Transmittable diseases, and Blood banking logistics; Immunohematology; Artificial and alternative

\section{Dovepress}

blood based therapeutics; Hematology; Biotechnology/nanotechnology of blood related medicine; Legal aspects of blood medicine; Historical perspectives. The manuscript management system is completely online and includes a very quick and fair peer-review system. Visit http://www.dovepress.com/ testimonials.php to read real quotes from published authors. 